\title{
PANDEMIA 2020 E EDUCAÇÃO
}

\author{
Juliana Berg ${ }^{1}$ \\ Carla Luciane Blum Vestena ${ }^{2}$ \\ Marlene Zwierewicz ${ }^{3}$ \\ Cristina Costa-Lobo ${ }^{4}$
}

Resumo: este ensaio teórico pretende oferecer aos educadores ambientais uma perspectiva epistêmica relacionada à educação, por meio de um novo pensar a partir da Pandemia criada pela COVID-19. Esse pensar fundamentase nos conceitos da complexidade e transdisciplinaridade, que são capazes de - por meio de projetos criativos ecoformadores, de uma nova racionalidade aberta, do pensar livre, multidimensional e multiocular - reorganizar ideias de forma ecossistêmica, oferecer criticidade e intelectualidade sistêmica, oportunizando a compreensão da diversidade e gerando bem-estar. Tais capacidades ampliadas no pensar sistêmico advêm da mudança do paradigma vigente, que não pode mais seguir lógica cartesiana, mas precisa se regenerar e renascer em respeito e consciência ampliados.

Palavras-chave: Educação; Complexidade; Transdisciplinaridade; Criatividade.

Abstract: this theoretical essay aims to offer environmental educators an epistemic perspective related to education, through a new thinking based on the Pandemic created by COVID-19. This thinking is based on the concepts of complexity and transdisciplinarity, which are capable - through creative ecotraining projects, of a new open rationality, of free, multidimensional and multiocular thinking - to reorganize ideas in an ecosystemic way, to offer systemic criticality and intellectuality, providing an understanding of diversity and generating well-being. Such expanded capacities in systemic thinking come from the change in the current paradigm, which can no longer follow Cartesian logic, but needs to regenerate and be reborn in expanded respect and awareness.

Keyword: Education; Complexity, Transdisciplinarity; Creativity.

${ }^{1}$ Universidade Federal do Paraná. E-mail: bergjuliana@gmail.com.

Link para o Lattes: http://lattes.cnpq.br/0468226628500580.

2 Universidade Federal do Paraná e Universidade Estadual do Centro-Oeste.

E-mail: cvestena@unicentro.br. Link para o Lattes: http://lattes.cnpq.br/0863582713179217.

${ }^{3}$ da Universidade Alto Vale do Rio do Peixe (UNIARP). E-mail: marlenezwie@yahoo.com.br.

Link para o Lattes: http://lattes.cnpq.br/2338653915538065.

4 Observatório Português da Presidência da UNESCO para a Juventude, Educação e

Sociedade. E-mail: cristinalobo@iesfafe.pt.

Link para o Lattes: https://www.researchgate.net/profile/Cristina Costa Lobo 


\section{Introdução}

A complexidade, com suas bases filosóficas, é considerada um dos campos mais férteis para o avanço científico na contemporaneidade, pois proporciona uma nova forma de compreensão da própria ciência e de seu papel. Tal novidade não se relaciona apenas ao conhecimento científico, mas simultaneamente à educação, ao agir em sociedade, ao meio ambiente e ao futuro da vida. Por isso, esse conceito exige o enfrentamento de questões éticas e educacionais que se tornaram fundamentais para o desenvolvimento intelectual escolar e acadêmico. Assim, discorre-se sobre a perspectiva da complexidade na educação ambiental como um meio de reflexão sobre o que se pretende de fato ensinar e sobre o que é essencial ao aprendizado das futuras gerações, principalmente após a pandemia da COVID-19.

Para tanto, por meio da obra do filósofo francês Edgar Morin, que apresenta um conjunto de estudos, pesquisas e reflexões sobre a complexidade, pretende-se discorrer a respeito da importância da transdisciplinaridade e criatividade enquanto elo de reflexão, questionamento e crítica entre sujeito e a realidade Considera-se que o pensamento pedagógico de Edgar Morin - sobretudo neste contexto de pandemias, precedido por violências instauradas em ambientes escolares, pelo quadro de repetências e evasões, pela perda de sentido do conhecimento - pode gerar novos enredos educacionais para seus atores, que são professores, alunos, pais, mães, responsáveis, líderes comunitários, educadores ambientais etc.

Para Morin (2013), por meio de pressupostos como uma nova racionalidade, o pensar livre, multidimensional e multiocular, foi possível reorganizar a forma tradicional de pensar, que é linear e binária, assimilando o saber simplificador, fragmentado e parcelar do especialista, fazendo-o crescer em complexidade.

A educação ambiental carrega em si complexidade, pois considera atitude social, liberdade, emoção e as conexões naturais provindas do existir corpo/mente, além de reconhecê-las em toda sua diversidade, totalidade e singularidade no meio ambiente (MORIN, 2000).

$\mathrm{Na}$ complexidade, considera-se 0 humano constituído no "entrelaçamento do emocional com o racional" (MATURANA, 2002, p. 18). Enquanto a emoção fundamenta e libera, o racional cria coerência operacional dos "sistemas argumentativos que construímos na linguagem, para defender ou justificar nossas ações". Assim, "não há ação humana sem uma emoção que a estabeleça como tal e a torne possível como ato" (MATURANA, 2002, p. 22).

Nesse sentido, acredita-se que é preciso pensar o ambiente natural e o humano no nível paradigmático ou "novo-paradigmático" em que há a seleção do que está aderido ao discurso e à teoria ou "posto de lado, rejeitado". Tal atenção faz com que haja a clareza de que no paradigma reside ordenamento lógico capaz de atribuir validade e universalidade à lógica adotada, a axiomas, conceitos, discursos e/ou teorias (MORIN, 2000, p. 25). 
Para Morin (2000), um dos saberes fundamentais no educar para o futuro é a identidade terrena, que se relaciona ao pensar nossa casa comum. Já enfrentamos outras pandemias que nos mostraram o quanto as diásporas motivadas por conquistas afetam os continentes, as pessoas e comunicações. A dominação e as violências sem consciência terrena trouxeram apenas destruição "pela escravidão e pela exploração feroz das Américas e da África" (p. 66). Outros vírus da Eurásia já invadiram esses continentes e semearam "varíola, herpes, gripo, tuberculose, enquanto levaram da América o treponema da sífilis que contaminou de sexo em sexo até Shangai" (MORIN, 2000, p. 66).

A COVID-19 não é a primeira ameaça, mas se tornou tão ou mais devastadora que aquelas que a antecederam. Isso por sua característica adaptável e flexível, sendo possível o seu contágio ocorrer em qualquer humano, independentemente de classe, idade, condições físicas, psicológicas ou educacionais. Além disso, a doença chegou num momento em que a mundialização se tornou unificadora de fronteiras e separadora da consciência terrena entre as pessoas (MORIN, 2000). Segundo o autor, isso ocorreu pelo desenvolvimento que nos chegou rapidamente sem que sequer percebamos, e não de forma experimentada, discutida, refletida.

Concebido unicamente de modo técnico-econômico, o desenvolvimento chega a um ponto insustentável, inclusive o chamado desenvolvimento sustentável. É necessária uma noção mais rica e complexa do desenvolvimento, que seja não somente material, mas também intelectual, afetiva, moral... (MORIN, 2000, p. 69-70).

Assim, a COVID-19 fechou escola após escola em todos os países gerando, em seus três primeiros meses de isolamento social, uma educação tecnológica advinda desse desenvolvimento técnico-econômico. Ela é considerada flexível por grande parte das instituições de ensino, mas ausente da presença humana e da percepção da realidade, frequentemente utilizando práxis distorcidas.

Nesse sentido, quem será o aluno que voltará à sala de aula? Quais serão os efeitos do aprendizado interrompido, da má nutrição, da confusão e do estresse vividos, de pais sem trabalho, do ensino a distância, da violência domiciliar, do próprio sentido de isolamento e de autoaprendizado?

Esse é o devir da educação contemporânea, que precisa tentar - sob matriz programática, sem identidade terrena e diante da incerteza do mundo atual e do conhecimento praticado - manter uma produção de ideias capazes de desenvolver o conhecimento do conhecimento e ir além, fazendo com que as pessoas reconheçam fatos e realidades e, a partir destes, desenvolvam a cooperação. 


\section{Pandemia por COVID-19 e a Educação}

A pandemia por COVID-19 assola o mundo em 2020, fazendo com que este ano demonstre o quanto a humanidade está despreparada para as incertezas mundiais, ficando também evidente o quanto o local influencia diretamente no global e vice-versa (MORIN, 2000).

Crianças e jovens enfrentam a crise em suas residências buscando resolver suas necessidades educacionais da forma como conseguem, enquanto uma grave crise econômica está em crescimento e o número de mortes aumenta. Será que os jovens estão compreendendo o que está acontecendo? Será que a educação colocou, mesmo que a distância, meios para contextualizar a gravidade do que a humanidade está enfrentando? Ou as crianças estão apenas naturalizando e/ou absorvendo os acontecimentos de forma própria, sendo desconsideradas em sua vulnerabilidade neste tempo de suspensão de atividades e isolamento?

Difícil saber. $O$ que se conhece é que a busca por evidências está em curso e ainda há muita incerteza, mesmo na ciência. Pesquisadores trabalham contra o tempo para que a vacina seja desenvolvida e a situação se "normalize". Entretanto, como pensar a educação durante e pós-pandemia?

Segundo Reimers e Schleicher (2020), pesquisadores da Escola de PósGraduação em Educação de Harvard e a Organização para a Cooperação e o Desenvolvimento Econômico (OCDE) há uma colaboração para gerar dados e evidências importantes aos governos dos países sobre o que é preciso para a educação nesse período. O objetivo é dar respostas educacionais rápidas à pandemia da COVID-19, todavia as dificuldades e a diversidade dos problemas se impõem, demonstrando não ser totalmente possível prever o futuro de forma assertiva. Até o momento, tem-se uma estrutura criada tem base na análise das necessidades e práticas globais atuais para apoiar a educação nos níveis mais básicos e que destaca ideias que estão surgindo, principalmente relacionadas às lideranças políticas de cada país (REIMERS; SCHLEICHER, 2020).

Assim, do que se conhece até meados de agosto de 2020, Reimers e Schleicher (2020) afirmam que o distanciamento social é a única alternativa para minimizar os efeitos de contágio, mortalidade e crise financeira advinda da suspensão da circulação de consumidores, pois quanto mais cedo se barrar a circulação do vírus, mais rapidamente as pessoas retornarão às suas atividades, e as crianças para as escolas.

No entanto, Reimers e Schleicher (2020) reconhecem que essa ação cooperativa entre os países é impossível, sobretudo porque, segundo os dados levantados por eles, as estruturas escolares, tecnológicas e principalmente de liderança governamentais são diversas e não cooperativas em escala global, sendo muitas vezes autoritárias e antiquadas em ideologias de enfrentamento global à adversidade que se apresenta. 
Nesse sentido, o Ocidente deverá sentir mais as infecções e a mortalidade devido ao clima e às estações mais frias do período de junho e julho de 2020, e a Ásia e a Europa deverão passar por outras ondas de contágio. Segundo previsão do Imperial College em Londres (2020), se a intervenção farmacêutica de natureza inovadora se mantiver, com testes de medicamentos já conhecidos para a minimização dos casos mais graves, espera-se que o impacto no ano de 2020 seja de 20 milhões de mortes no mundo, caso contrário, estima-se que possam chegar a 40 milhões (REIMERS; SCHLEICHER, 2020).

Nesse sentido, afirma-se que as economias e populações mais vulneráveis, sendo as crianças um grupo considerado importante nesse cenário, deverão sofrer as consequências das decisões de seus líderes, que serão maiores nos países que retardarem o isolamento para a contenção da circulação do vírus, uma vez que nesses países o problema perdurará por mais tempo (REIMERS; SCHLEICHER, 2020).

Além disso, considera-se que a defasagem escolar deva igualmente crescer, pois a diferença entre os alunos e o pouco apoio familiar deverão aumentar as discrepâncias, principalmente por consequência da crise financeira. Assim, às escolas caberá a missão de se aproximar de seus alunos com os meios disponíveis e possíveis.

Segundo Huang et al. (2020), cada país traçou suas metas e adotou "meios de sustentar a educação diante do quadro de distanciamentos, entretanto, o fechamento das escolas está gerando altos custos sociais para pessoas e comunidades" (BERG; VESTENA; COSTA-LOBO, 2020). Assim, já é possível considerar as seguintes consequências (Quadro 1):

Quadro 1: Consequências da COVID-19: Pandemia e Isolamento Social e Escolar.

\begin{tabular}{|l|l|}
\hline Aprendizado interrompido & $\begin{array}{l}\text { A escolaridade fornece aprendizado essencial e, quando as } \\
\text { escolas fecham, crianças e jovens ficam sem oportunidades } \\
\text { de crescimento e desenvolvimento. }\end{array}$ \\
\hline Má nutrição & $\begin{array}{l}\text { Muitas crianças e jovens dependem das refeições gratuitas } \\
\text { ou com desconto fornecidas nas escolas para uma nutrição } \\
\text { saudável. Quando as escolas fecham, a nutrição fica } \\
\text { comprometida. }\end{array}$ \\
\hline $\begin{array}{l}\text { Confusão e estresse para os } \\
\text { professores }\end{array}$ & $\begin{array}{l}\text { Quando as escolas fecham, especialmente inesperadamente } \\
\text { e por períodos desconhecidos, os professores geralmente } \\
\text { não têm certeza de suas obrigações e de como manter } \\
\text { conexões com os alunos para apoiar o aprendizado. As } \\
\text { transições para plataformas de aprendizagem a distância } \\
\text { tendem a ser confusas e frustrantes, mesmo nas melhores } \\
\text { circunstâncias. Em muitos contextos, o fechamento da escola } \\
\text { leva a licenças ou separações para os professores. }\end{array}$ \\
\hline $\begin{array}{l}\text { Quando as escolas fecham, os pais geralmente são } \\
\text { solicitados a facilitar o aprendizado das crianças em casa e } \\
\text { educação a distância e em se esforçar para realizar essa tarefa. Isso é } \\
\text { casa }\end{array}$ & $\begin{array}{l}\text { especialmente verdade para pais com educação e recursos } \\
\text { limitados. }\end{array}$ \\
\hline
\end{tabular}


...continuação.

\begin{tabular}{|c|c|}
\hline $\begin{array}{l}\text { Desafios na criação, } \\
\text { manutenção e melhoria do } \\
\text { ensino a distância }\end{array}$ & $\begin{array}{l}\text { A demanda por ensino a distância dispara quando as escolas } \\
\text { fecham e geralmente sobrecarregam os portais existentes } \\
\text { para educação remota. Mover o aprendizado das salas de } \\
\text { aula para as casas em grande escala e com pressa apresenta } \\
\text { enormes desafios, tanto humanos quanto técnicos. }\end{array}$ \\
\hline $\begin{array}{l}\text { Lacunas na assistência à } \\
\text { infância }\end{array}$ & $\begin{array}{l}\text { Na ausência de opções alternativas, os pais que trabalham } \\
\text { frequentemente deixam as crianças sozinhas quando as } \\
\text { escolas fecham e isso pode levar a comportamentos de risco, } \\
\text { incluindo maior influência da pressão dos colegas e abuso de } \\
\text { substâncias. }\end{array}$ \\
\hline Altos custos econômicos & $\begin{array}{l}\text { Os pais que trabalham são mais propensos a faltar ao } \\
\text { trabalho para cuidar de seus filhos quando as escolas } \\
\text { fecham. Isso resulta em perda de salário e tende a impactar } \\
\text { negativamente a produtividade. }\end{array}$ \\
\hline $\begin{array}{l}\text { Tensão não intencional nos } \\
\text { sistemas de saúde }\end{array}$ & $\begin{array}{l}\text { Os profissionais de saúde com crianças não podem } \\
\text { frequentar o trabalho facilmente devido às obrigações de } \\
\text { assistência à infância resultantes do fechamento da } \\
\text { escola. Isso significa que muitos profissionais médicos não } \\
\text { estão nas instalações onde são mais necessários durante } \\
\text { uma crise de saúde. }\end{array}$ \\
\hline $\begin{array}{l}\text { Maior pressão sobre as } \\
\text { escolas que permanecem } \\
\text { abertas }\end{array}$ & $\begin{array}{l}\text { O fechamento de determinadas escolas sobrecarrega as } \\
\text { outro ponto do sistema educacional, pois há um } \\
\text { redirecionamento para outras unidades escolares que } \\
\text { permanecem abertas e acabam ficando com número } \\
\text { excessivo de crianças. }\end{array}$ \\
\hline $\begin{array}{l}\text { Aumento nas taxas de } \\
\text { evasão escolar }\end{array}$ & $\begin{array}{l}\text { É um desafio garantir que crianças e jovens retornem e } \\
\text { permaneçam na escola quando as escolas reabrem após o } \\
\text { fechamento. Isso se aplica especialmente a fechamentos } \\
\text { prolongados e quando choques econômicos pressionam as } \\
\text { crianças a trabalhar e gerar renda para as famílias com } \\
\text { problemas financeiros }\end{array}$ \\
\hline $\begin{array}{l}\text { Maior exposição à violência e } \\
\text { à exploração }\end{array}$ & $\begin{array}{l}\text { Quando as escolas são fechadas, o casamento precoce } \\
\text { aumenta, mais crianças são recrutadas em milícias, a } \\
\text { exploração sexual de meninas e mulheres jovens aumenta, a } \\
\text { gravidez na adolescência se torna mais comum e o trabalho } \\
\text { infantil cresce. }\end{array}$ \\
\hline Isolamento social & $\begin{array}{l}\text { As escolas são polos de atividade social e interação } \\
\text { humana. Quando as escolas fecham, muitas crianças e } \\
\text { jovens perdem o contato social que é essencial para a } \\
\text { aprendizagem e o desenvolvimento. }\end{array}$ \\
\hline $\begin{array}{l}\text { Desafios para medir e validar } \\
\text { o aprendizado }\end{array}$ & $\begin{array}{l}\text { Avaliações agendadas - principalmente exames de alto risco } \\
\text { que determinam admissão ou avanço para novos níveis e } \\
\text { instituições de ensino - são desarmadas quando as escolas } \\
\text { fecham. As estratégias para adiar, pular ou examinar os } \\
\text { administradores à distância levantam sérias preocupações } \\
\text { sobre a justiça, principalmente quando o acesso ao } \\
\text { aprendizado se torna variável. As interrupções nas avaliações } \\
\text { resultam em estresse para os alunos e suas famílias e podem } \\
\text { desencadear o desengajamento. }\end{array}$ \\
\hline
\end{tabular}

Fonte: HUANG et al. (apud BERG, 2020), Vestena e Costa-Lobo (2020).

Revbea, São Paulo, V. 15, № 4: 470-487, 2020. 
Portanto, considera-se que, neste momento de enfrentamento da pandemia, à escola está atribuída a importante função social e educacional de - além da suspensão das aulas e consequente isolamento como medida de frear o contágio - transmitir conhecimento, apoiar emocionalmente os estudantes, contextualizar o que está ocorrendo e estar à disposição do aluno e de seus pais, buscando evitar a ampliação das vulnerabilidades e manter um clima familiar menos adverso diante da adaptação a esse período de incertezas.

Além disso, cabe à educação neste momento refletir sobre o futuro e visionar que educação quereremos após 2020 e além? De racionalidade aberta propensa a conhecer melhor as realidades e vivenciá-las para, então, transformá-las? Ou de pensamento cartesiano e racionalidade especializada?

\section{Mudança e Transdisciplinaridade}

Se é preciso reforma nos meios de ensino para uma aprendizagem renovada, há igualmente necessidade de reflexão sobre outro ponto: "não se pode reformar a instituição, se anteriormente as mentes não forem reformadas; mas só se pode reformar as mentes se a instituição for previamente reformada" (MORIN, 2000, p. 22).

Segundo Morin (2000, p. 22), tal reforma pode acontecer desde a escola primária, partindo "das grandes interrogações da curiosidade infantil, que dever-se-iam manter igualmente como interrogações do adulto: 'Quem somos, de onde viemos, para onde vamos'."

Já no ensino secundário, há de se estabelecer a comunicação como base. Assim, o diálogo entre a cultura das humanidades e a cultura científica associado à valorização do passado - resultaria em um tipo de conhecimento que já se tornou complexo, abarcando aspectos da realidade humana e da realidade ambiental (MORIN, 2000).

A universidade, enquanto entidade que "conserva, memoriza, integra e ritualiza uma herança cultural de saberes, ideias e valores", precisa reexaminar-se, atualizar-se e regenerar-se. Nela um objetivo vital pode ser atingido: "uma reforma do pensamento que viabilize e permita o emprego total da inteligência. Trata-se de uma reforma não pragmática, mas paradigmática, concernente à nossa aptidão para organizar o conhecimento" (MORIN, 2000, p. $15 ; 21)$.

Essa reforma precisa ser iniciada pela articulação entre os saberes e deve partir dos professores. Ela deve ser originada e estimulada por uma educação que reconheça igualmente sua identidade terrena e, por meio desta, busque renascer o humano de modo conectado ao meio ambiente. Assim, assume importância a transdisciplinaridade, caracterizada por proporcionar em sua prática, esquemas cognitivos capazes de atravessar as disciplinas, coloca- 
las em sinergia, proporcionar o pensar e o refletir, "por vezes com uma tal virulência que as coloca em transe" (MORIN, 2000, p. 51).

Nesse sentido, Morin (2000) coloca, mesmo sem a intenção de ajuste e enquadramento, formas de conceber e pensar o Projeto Político Pedagógico (PPP) para um sistema educacional que pode - guardada a importância da ação local e global e sua incerteza implícita - revolucionar as formas de pensar currículo, ambiente, didática, políticas, entre outros.

Nessa concepção, a escola passa a ser um lugar - no sentido cultural -, mesmo que muitas vezes sem espaço fixo, de discussão de ideias e contrapontos fundamentados, orientados por uma cultura de respeito à pessoa e de desenvolvimento no seu tempo singular e cultural. Esse lugar considera também os recursos disponíveis, principalmente os advindos da natureza, visando sua autorregeneração.

Segundo Moraes (2015, p. 64), na ontologia complexa, o humano está no mundo e é parte dele, como organização ativa, produto de interações que matem igualmente a "tensão das polaridades constitutivas do ser, reconhecendo as interações ocorrentes entre as distintas dimensões".

Moraes e Batalloso (2015, p. 143) acreditam que esta crise atual da saúde é, antes de tudo, uma crise ética, que "trouxe consigo o enfraquecimento da responsabilidade e da solidariedade", desfazendo relações humanas e aniquilando dispositivos "produtores de sentido como a educação, a religião, a ética, a arte, entre outros". Sabe-se igualmente que ética é de natureza transdisciplinar, uma vez que "perpassa toda ação, ou processo educacional transversalmente", sendo todo seu processo educativo fundamentado e relacionado com "valores" nos quais "não existe lugar para a neutralidade" (p.147).

Segundo Moraes e Batalloso (2015, p. 148), em toda Pedagogia, ou forma de pensar e educar, estão implicadas ao mesmo tempo "aposta $e$ estratégia, ou seja, uma pedagogia da consciência e do compromisso, da reflexão e da ação". Por outro lado, deve-se permanecer em vigia sobre as formas de pensar, assim "é preciso levar em conta que os fatos e processos educacionais não podem ser reduzidos a uma classificação, etiquetação, uniformização ou divisão aritmética de atividades educativas, simplesmente porque o desenvolvimento humano não é isomorfo [...]", portanto "sempre haverá algo cujo valor educativo não pode ser reduzido a uma única dimensão ou a um mesmo nível de realidade".

Para Santos e Santos (2015, p. 129), atividades como a composição de um currículo escolar, por exemplo, exigem interlocução entre criatividade e diálogo, pois se caracterizam por serem elaboradas por decisões coletivas. Assim, tal integração também propõe "transdisciplinaridade como princípio teórico-metodológico", porque nesse caso as disciplinas se fazem a partir da complementaridade mútua. 
Petraglia (2013, p. 108-109) acredita que, se há uma finalidade para a educação, está em tornarmo-nos livres e felizes, e a transdisciplinaridade e 0 pensamento complexo são os "elos orgânicos" para isso.

Assim sendo, o contexto atual pede humanos integrados em sua complexidade. Para isso, são necessárias escolas que caminhem em direção à evolução transdisciplinar, que, segundo Nicolescu (1999, p. 8), tem no prefixo trans a indicação do que está ao mesmo tempo entre disciplinas, através das diferentes disciplinas e além de qualquer disciplina.

Segundo Suanno (2015, p. 207), a transdisciplinaridade contém interdisciplinaridade e vai além, uma vez que incorpora "diferentes formas de conhecimentos e saberes (experenciais, filosóficos, culturais, literários, tradições, mitos, lendas etc.)".

Para Suanno (2013), transdisciplinaridade é "pulsão religadora que articula razão, emoção e atitude transformadora, tralhando assim como uma razão sensível e uma práxis complexa e transdisciplinar", com a finalidade de produzir conhecimento que mude a realidade, de forma a se tornar desafio e inspiração "com potencial construtivo e transformador, pois, ao transcender as disciplinas as incorpora, assim como rompe com a linearidade $e$ a fragmentação do conhecimento" advindos de educação tradicional (SUANNO, 2015, p. 207-208).

$\mathrm{Na}$ aprendizagem, as práticas transdisciplinares: reintroduzem o sujeito cognoscente; possibilitam autoconhecimento, autocrítica, tomada de consciência e autopoiese; estudam o destino multifacetado do humano; compreendem a simplificação e a complexidade em relação mútua; reconhecem a pluralidade cultural; religam cultura científica e cultura das humanidades; educam para a resiliência; promovem o sentipensar; trabalham a multidimensionalidade humana; promovem processos de ensino e pesquisa; criam ambientes de aprendizagens saudáveis; criam representações visuais de conceitos e dinâmicas de interação; favorecem processos de autoformação; relacionam ciência, docência e consciência; promovem metamorfose social, individual e antropológica, dentre outros (SUANNO, 2015, p. 209-210).

Segundo Moraes (2015, p. 69), trabalha-se transdisciplinaridade "em nível de conteúdos disciplinares, integrando, portanto, diferentes domínios linguísticos ou dimensões fenomenológicas da realidade" sem esperar que o resultado do conhecimento produzido ao final se enquadre em algum deles, pois o conhecimento produzido vai além.

Segundo Nicolescu (1999, p. 10), a importância da transdisciplinaridade é aparente, principalmente na ciência da complexidade, porém é preciso inovar e evitar erros comuns, como confundir tal educação com pluridisciplinaridade ou interdisciplinaridade. É preciso considerar que, mesmo com os desafios impostos qualquer pedagogia está sujeita aos desvios mercantilistas e à procura por meios de dominação, além da tentativa de "verter o nada no vazio, mediante a adoção de um slogan de 'bom-tom' desprovido de qualquer 
conteúdo". Ademais, ela não pode ter seu caráter associado à linearidade disciplinar que, segundo Ribeiro e Moraes (2014, p. 241), "determina a existência de um único nível de Realidade".

Nesse sentido, segundo Moraes (2015, p. 83), "ao transcender a lógica binária, fragmentadora da realidade, ao resgatar a dimensão complementar das polaridades aparentemente contrárias", a abordagem transdisciplinar promove a alteridade, pois, quando "resgata o respeito ao pensamento do outro que, embora seja diferente do meu, é absolutamente legítimo", reconhece igualmente "a importância dos conhecimentos antigos e a necessidade de explorar outras maneiras de ser/conhecer, de viver/conviver e aprender", favorecendo igualmente a ecologia dos saberes.

De acordo com Moraes (2015), para integrar as principais dimensões constitutivas de uma visão transdisciplinar na educação, é preciso saber que elas estão fortemente vinculadas, mediante diferentes tipos de relações que constituem a matriz de onde devem partir possíveis indicadores capazes de descrever uma escola como transdisciplinar nas seguintes dimensões: ecossocial e planetária; psicofísica, corporal, emocional e cognitiva; criativa e estética; e ambiental e política. Nesse sentido, o conhecimento transdisciplinar assume ideário de produto de tessitura complexa, dialógica e autoecoorganizadora expressando continuidade e cada vez maior aprofundamento (RIBEIRO; MORAES, 2014).

Com base no todo, percebe-se que a propensão da mente humana para formular e solucionar problemas traz a discussão para uma escola transdisciplinar que precisa de didáticas e métodos de ensino/aprendizagem diversos dos adotados nas escolas tradicionais, pois, para o pensamento complexo, para o nascimento de uma nova forma de pensar e de um novo humano, é preciso aprender a criar.

\section{Projetos Ecoformadores Transdisciplinares}

No retorno às aulas, após a pandemia, encontraremos alunos iguais ou diferentes? Certamente não serão aqueles, de antes, teremos outros alunos, advindos de contexto cujo ciclo de interrupções e reflexões relativas ao que foi a pandemia por COVID-19. Alunos que precisam de acolhimento relativo as suas demandas psicossociais e da discussão quanto ao porquê de prevenção e do isolamento.

Haverá mudanças no futuro após a pandemia e, pormínimas que sejam, elas necessitam ser trabalhadas em todos os âmbitos da educação ambiental. É dos educadores ambientais a missão de contextualizar, transdisciplinar os conteúdos relacionando-os ao que ocorreu e provocar seus alunos à reflexão, ao questionamento, desabafo e entendimento ambiental.

Assim como Berg, Vestena e Costa-Lobo (2020), acredita-se ser necessário, ao retornar às aulas, (re)conhecer as crianças e os jovens que 
novamente estarão em sala, questionando-os sobre suas percepções e vivências. Assim, é possível traçar planos para reflexões sobre sua experiência pandêmica, as disciplinas e a educação ambiental, tecendo um novo pensar.

Projetos ecoformadores são uma excelente alternativa, uma vez que são inclusivos por natureza e se utilizam das "especificidades que compõem a diversidade, seja ela física, cultural, cognitiva, emocional" etc., além de proporcionarem ressignificação ao que já se conhece na prática ambiental (PRAUN; GONÇALVES, 2009, p. 143).

$\mathrm{Na}$ ecoformação, há a transposição para uma educação de princípios transdisciplinares quando há a "interação da pessoa ao seu entorno de forma sustentável', pois se considera em tais projetos educacionais a prática contextualizada na interação do aluno com o meio (PRAUN; GONÇALVES, 2009, p. 144).

Assim, projetos ambientais ecoformadores são inspirados na educação preconizada por Dewey, que acreditava em experiências que movessem e motivassem as pessoas para a efetividade da aprendizagem. Entretanto, para que esses projetos ocorram, segundo Torre e Zwierewicz (2009, p. 154), devese contemplar

[...] a problemática sentida e a intenção e fixação de objetivos ou metas; coleta de dados, informações e referenciais para solucionar a problemática apresentada; elaboração de propostas, hipóteses ou possíveis soluções; confirmação, resolução ou resultados obtidos e sua comunicação.

Igualmente, deve-se considerar que um projeto ecoformador é criativo por natureza, pois o pensar e a busca pela conexão entre as pessoas e o ambiente advêm da criatividade dos alunos.

Um Projeto Criativo Ecoformador representa um referencial de ensino e de aprendizagem baseado na autonomia, na transformação, na colaboração e na busca do desenvolvimento integral da pessoa (TORRE; ZWIEREWICZ, 2009, p. 155).

Esses são projetos que buscam a consciência do que se encontra intrínseco e extrínseco ao sujeito e os colocam em dialógica com o sentipensar, ao criar, experimentar e vivenciar conteúdos e vê-los existindo em teoria e prática (TORRE; ZWIEREWICZ, 2009).

Segundo Zwierewicz et al. (2019), Torre e Zwierewicz (2009) desenvolveram os Projetos Criativos Ecoformadores (PCE) como uma metodologia que pressupõe que esse seja "[...] ancorado na vida, estimulando que os docentes e estudantes possam ir além da reprodução de 
conhecimentos e além da análise crítica da realidade [...]" (ZWIEREWICZ, 2013, p. 166).

Assim, "transitar de práticas tradicionais para processos de ensino e de aprendizagem norteados pela educação complexa é um grande desafio", entretanto isso é possível, uma vez que "ao se estimular a religação dos conhecimentos, como defende González Velasco (2017)", possamos inspirar olhares, renovar práticas, conscientizar amplamente sobre a relação entre o que é vivo e o que morre (ZWIEREWICZ et al., 2019, p. 120) .

Para o desenvolvimento de Projetos Criativos Ecoformadores, são necessários os seguintes organizadores procedimentais descritos no Quadro 2.

Quadro 2: Organizadores Procedimentais do Projeto Criativo Ecoformador.

\begin{tabular}{|l|l|}
\hline $\begin{array}{l}\text { Epítome ou campo } \\
\text { formativo }\end{array}$ & $\begin{array}{l}\text { Estrutura conceitual, referencial temático, campo de atuação ou } \\
\text { ponto central de trabalho. }\end{array}$ \\
\hline $\begin{array}{l}\text { Legitimação teórica e } \\
\text { pragmática }\end{array}$ & $\begin{array}{l}\text { Fundamentação teórica atual e de impacto, contextualização da } \\
\text { demanda, da circunstância, do ambiente e das pessoas, assim } \\
\text { como de sua cultura. Questionar: o quê? Por quê? Quem? Onde? }\end{array}$ \\
\hline $\begin{array}{l}\text { Questionamento, } \\
\text { problemática } \\
\text { perguntas geradoras }\end{array}$ & $\begin{array}{l}\text { Questionar: para qual finalidade? A quem se destina? Quem se } \\
\text { beneficia? Que problemas aparecerão e como os abordaremos? }\end{array}$ \\
\hline $\begin{array}{l}\text { Metas como eixos } \\
\text { norteadores }\end{array}$ & $\begin{array}{l}\text { Aspirações e objetivos pretendidos em distintas modalidades, tais } \\
\text { como conhecimentos, competências, atitudes, hábitos, } \\
\text { sentimentos, habilidades etc. }\end{array}$ \\
\hline Rotas, itinerários & $\begin{array}{l}\text { Metodologia, estratégias, atividades a serem feitas de forma } \\
\text { flexível, dinâmica, aberta à incerteza, interativa, autopoiética, } \\
\text { coerente com o olhar ecoformador. }\end{array}$ \\
\hline $\begin{array}{l}\text { Coordenadas temporais } \\
\text { ou plano }\end{array}$ & Visão temporal, ou seja, quando? \\
\hline Avaliação emergente & $\begin{array}{l}\text { Todas as perguntas anteriores precedidas de: como se sentiram? } \\
\text { O que aprenderam? }\end{array}$ \\
\hline Polinização & Processo ecoformador de continuidade e de retroalimentação. \\
\hline
\end{tabular}

Fonte: As autoras a partir de Torres e Zwierewicz (2009, p. 155-162).

O projeto de Debiasi (2009), a partir do projeto Homem e Natureza: conscientizar para recomeçar, desenvolvido junto ao ensino fundamental de uma escola catarinense, é um exemplo de proejto criativo ecoformador, pois buscou provocar a reflexão sobre os recursos naturais de maneira consciente e responsável, problematizando as atitudes do homem em relação à natureza.

Nesse, foram estabelecidas comparações sobre as formas de exploração dos recursos naturais a partir de processos revolucionários e criativos da humanidade, que mudaram a relação humana e a história; partiuse da realidade local, então comparando-a com a realidade mundial. A 
descoberta do fogo foi problematizada e pesquisada, assim como a Revolução Industrial e as máquinas que a impulsionaram. Muitas questões foram levantadas, como "até que ponto é benéfica toda a intervenção realizada historicamente pelo homem na natureza?" Dentre outros elementos organizadores do projeto, uma das metas foi o desenvolvimento criativo e sustentável de produtos que gerassem efeito positivo no meio ambiente (DEBIASI, 2009).

Já a tecnologia como ferramenta educacional foi problematizada com jovens do ensino médio quando da utilização de jogos mistos - que mesclam tecnologia e realidade - no estudo de Maraschin et al. (2016). O projeto desenvolvido colocou jovens em territórios desconhecidos, por meio de sociotécnica para agenciar movimentos de territorialização e desterritorialização capazes de produzir efeitos de reconfiguração da política cognitiva do espaço da criança, induzindo que os participantes repensassem o conceito de experiência programada.

Maraschin et al. (2016) adotaram visão sistêmica e complexa da cognição, pois buscaram fundamentação teórica e aporte científico na Ecologia Cognitiva de Pierre Lévy (1993) e na Política Cognitiva de Kastrup (1999), concebendo um novo jogo para o estímulo da cognição em vivência coletiva e ambiente natural junto às ferramentas tecnológicas.

A cognição foi considerada a partir da sua "concepção processual e inventiva, inserida nas práticas e nas políticas que a engendram e nos processos que the dão forma, reconhecendo sua dimensão espaço/temporal/coletiva e de permanente transformação", e também sua imprevisibilidade devido às transformações no território, que são propositais (MARASCHIN et al., 2016, p. 214). Tal conceito se aproxima ao de autopoiese enquanto ampliação da mente em processo de aprendizagem que relaciona todas as funções cognitivas (ALMEIDA, 2015).

Segundo Maraschin et al. (2016, p. 214),

Os chamados jogos de localização se desenvolveram a partir do encontro entre os videogames e as mídias locativas baseadas em GPS (Global Positioning System) ou sistema de triangulação de sinal "telefônico" (LEMOS, 2010). Trata-se de uma modalidade de jogos nos quais diversos jogadores podem compartilhar estratégias de colaboração ou competição que se desenrolam utilizando um necessário acoplamento entre software e território. 
espaço, definido pelos autores como "tecnogeográfico", torna-se mais complexo e provoca seus jogadores à execução de tarefas reais como plantar, colher ou regar (MARASCHIN et al., 2016).

Maraschin et al. (2016, p. 220) acreditam que o jogo em análise compõe ferramenta lúdica e didática capaz de provocar resultados ainda a serem estudados, mas que encontram embasamento na teoria fundamentada. Assim, sugere-se como pesquisa futura que se encontrem meios de analisar as funções cognitivas demonstradas por Almeida (2015) como possíveis parâmetros a serem adotados, mas que não se perca a análise ambiental e comportamental durante esse processo.

Segundo Vestena e Vestena (2020, no prelo), sob a perspectiva da espacialização de casos da COVID-19 e da Geografia, por exemplo, é possível conceber forma e método para ocorrer sensibilização e conscientização ambiental. Nesse sentido, o PCE voltado à espacialização auxiliará no desenvolvimento da percepção do risco à COVID-19 e, consequentemente, na adoção de atitudes e procedimentos de segurança que impactarão na redução de risco a desastre, gerando consciência ambiental.

Diante disso, a superação do academicismo é um dos desafios que afastam a capacidade de análise e consciência do que é vivo e rico em subjetividade, que detém movimento e que se transforma com o tempo daquilo que é conhecimento teórico. Assim, numa tentativa de ligar tal ideal aos PCEs, Saturnino de la Torre, da Universidade de Barcelona (Espanha), e Marlene Zwierewicz, da UNIBAVE/UNIARP de Santa Catarina (Brasil), trabalharam no modelo de Escola Criativa defendido junto à Red de Escuelas Creativas (Espanha), que no ano de 2012 expandiu territórios reunindo países na Europa aos das Américas (TORRE, 2009).

A Rede Internacional de Escolas Criativas (RIEC) busca, por meio dos PCEs, polinizar a criatividade e fortalecer o professor, compreendendo a formação docente como aquela que

[...] desperte a consciência e a capacidade de planejar, atuar, avaliar e redefinir o processo educativo; promova uma forma própria de reformar a instituição e o pensamento, compatível com as necessidades que sente a equipe envolvida, bem como as despertadas em âmbito global; o fortalecimento da resiliência dos gestores, dos docentes e da equipe técnica para que conheçam suas potencialidades em criar uma forma inovadora de reformar, ao mesmo tempo, a instituição e o pensamento dos profissionais que nela atuam; a proposição de um ensino que tenha como ponto de partida e de chegada "a própria vida"; e o envolvimento da equipe em estratégias de polinização para que, além de fortalecer a resiliência ao observar seus próprios avanços, ajude outros profissionais e instituições que também buscam superar o ensino linear (ZWIEREWICZ, 2013, p. 171-172). 
A RIEC atua com gestão integrada à coordenação nacional em vários estados brasileiros, mantendo seu foco na construção de uma escola rica e pautada no rigor científico, contribuindo com o pensamento complexo, a polinização da criatividade, o respeito ao ambiente natural e a própria natureza. Por isso, demonstra-se assim como a educação ambiental, o meio pedagógico e metodológico rigoroso e impulsionador da mudança do que é cartesiano e que tantos malefícios têm provocado às pessoas, principalmente a sua subjetividade e bem-estar físico, intelectual e emocional.

Em julho de 2019, novos núcleos foram criados, dois deles são o Núcleo RIEC da Universidade Estadual do Centro Oeste (Unicentro), localizado na cidade de Guarapuava (Paraná) - o primeiro no estado com foco na capacitação docente, polinização da criatividade e inclusão de alunos altamente habilidosos, pois a região vem demonstrando ser polo nos estudos relativos à superdotação; e o Núcleo RIEC Instituto de Estudos Superiores de Fafe (IESF) Amarante, localizado na homônima cidade portuguesa criativa da música, cujo foco é o desenvolvimento da criatividade para potencializar aspectos cognitivos e relacionais nos jovens, promovendo 0 empreendedorismo e a orientação vocacional, contando com o apoio das organizações CIDI-IESF, Cátedra UNESCO de Juventude, Educação e Sociedade e Optimus Creative and Technology School. Além dos objetivos já mencionados, os núcleos são vinculados ao Laboratório de Pesquisas em Psicologia Educacional (LAPE) da Unicentro, onde são desenvolvidas pesquisas científicas e livros acadêmicos que são referências internacionais.

\section{Considerações finais}

A escola está se tornando um lugar diferente e, mesmo que não demonstre tantas mudanças depois da Pandemia de 2020, é certo que desvios à racionalidade cartesiana surgirão com potencial de serem fortalecidos. Assim, tornou-se urgente investir em educação que provoque forma de pensamento capaz de analisar problemas e conflitos em diferentes domínios, habilidade de antecipar, compreender e avaliar futuros próximos, negociar normas e valores impostos, desenvolver coletivamente ações inovadoras, colaborar, compreender, respeitar, sensibilizar-se e lidar com conflitos ambientais e sociais que surjam (UNESCO, 2017).

Portanto, precisa-se de um melhor aproveitamento do tempo no sentido de estarmos a trabalho do futuro. pois, de acordo com Moraes (2015, p. 17), não podemos investir sob um pensamento tradicional e chegarmos ao mesmo ponto de partida atual, que revela o adoecimento da escola que exclui o sujeito e sua cultura, privilegiando conteúdo, uma vez que tal patologia induz à fragmentação do ser humano, negando suas emoções, "seus desejos e seus sentimentos e afetos, suas dimensões globais constitutivas do operar".

Para Morin (2007, p. 93), a educação e o pensar clássico possibilitaram ao homem desaprender a compreensão de si mesmo, promoveram 
autoenganos em suas relações uns com outros. Isso provocou competição, autoilusão, autojustificação e cóleras "que nos permitem expulsar do outro e, ao mesmo tempo, eliminar em nós mesmos qualquer lucidez" (TRIANDIS, 2013).

Portanto, segundo Petraglia e Gonçalves (2012), nosso século já está marcado por mudanças e a COVID-19 acelerou algumas delas, nas relações humanas, na ciência, tecnologia e cultura, assim como no sentir e pensar e nas atividades cognitivas. Isso demonstra que há motivos e interesse para gerar novas soluções nas escolas, na sociedade, local e globalmente. Há também urgência por aprendizagem criativa, uma vez que essa resulta em mentes flexíveis e em plenitude das capacidades e habilidades úteis para o bem-estar vocacional e social, contribuindo significativamente para a aquisição da informação e do conhecimento, uma vez que prioriza o desenvolvimento prático e necessita, para isso, da consubstanciação ao surgimento de funções cognitivas superiores.

Concerne à educação uma grande jornada para atualizar e readequar o modelo tradicional ao que está por vir, pois a pandemia acelerou tal propensão. Portanto, entende-se que para os educadores ambientais surge uma grande possibilidade de transformar a relação das pessoas com seu meio, valorizando a importância deste pois, diante da falta deste elo orgânico fundamental e de sua manipulação indiscriminada, novas pandemias nos surpreenderão e novamente repetiremos ciclos de autoengano.

\section{Agradecimentos}

Juliana Berg é Bolsista Capes e Carla Luciane Brum Vestena é Bolsista de Produtividade da Fundação Araucária, instituições às quais as autoras agradecem.

\section{Referências}

ALMEIDA, L. S. Programas de Treino cognitivo: ajudar os alunos a aprender e pensar. In: MIRANDA G.L.; BAHIA S. Psicologia da Educação: temas de desenvolvimento, aprendizagem e ensino. Lisboa: Relógio D’Água Ed., 2015.

BERG, J.; VESTENA, C. L. B.; COSTA-LOBO, C. Criatividade e Autonomia em Tempo de Pandemia: Ensaio Teórico a partir da Pedagogia Social. Revista Internacional de Educación para la Justicia Social, 9(3e), p. 420-433, 2020.

DEBIASI, M. C. Projeto Homem e Natureza: conscientizar para recomeçar. In: ZWIEREWCZ, M.; TORRE, S. De La. Uma escola para o Século XXI: Escolas criativas e resiliência na educação. Florianópolis: Insular, 2009.

HUANG, R. H.; LIU, D. J.; TLILI, A.; YANG, J. F.; EWANG, H. H. Handbook on facilitating flexible learning during educational disruption: The chinese experience in maintaining undisrupted learning in COVID-19 outbreak. Institute of Beijing Normal University, 2020. 
KASTRUP, V. A Invenção de Si e do Mundo: uma introdução do tempo e do coletivo no estudo da cognição. São Paulo: Papirus, 1999.

LEMOS, A. Jogos móveis locativos: Cibercultura, espaço urbano e mídia locativa. Revista USP, São Paulo, n. 86, p. 54- 65, 2010.

LÉVY, P. As tecnologias da inteligência: o futuro do pensamento na era da informática. Rio de Janeiro: Ed. 34, 1993.

MARASCHIN, C.; BAUM, C.; TELES, F.; ROOS, R. Tecnogeografias: modulações nas ecologias e políticas cognitivas. Fractal: Revista de Psicologia, v. 28, n. 2, p. 213-220, 2016.

MATURANA, H. Emoções e Linguagem na Educação e na Política. Belo Horizonte: Editora UFMG, 2002.

MORAES, M. C. Transdisciplinaridade, criatividade e educação: fundamentos ontológicos e epistemológicos. Campinas: Papirus, 2015.

MORAES, M. C.; BATALOSSO, J. M. Um olhar complexo e transdisciplinar sobre ética e educação. In: BEHRENS, M. A.; ENS, R. T. Complexidade e Transdisciplinaridade: novas perspectivas teóricas e práticas para a formação de professores. Curitiba: Appris, 2015.

MORIN, E. A religação dos saberes: o desafio do século XXI. Rio de Janeiro: Bertrand Brasil, 2013.

MORIN, E. Educação e Complexidade: os sete saberes e outros ensaios. São Paulo: Cortez, 2007.

MORIN, E. Introdução ao Pensamento Complexo. Porto Alegre: Sulina, 2005.

MORIN, E. Os sete saberes necessários à educação do futuro. São Paulo: Cortez; Brasília: UNESCO, 2000.

NICOLESCU, B. O Manifesto da Transdisciplinaridade. São Paulo: TriTon, 1999.

PETRAGLIA, I. Pensamento complexo e educação. São Paulo: Editora Livraria da Física, 2013.

PETRAGLIA, I.; GONÇALVES, N. Cultura, Identidade e Educação. In: ALMEIDA, C.; PETRAGLIA, I. et al. Estudos de Complexidade. São Paulo: Xamã, 2012.

PRAUN, A. G.; GONÇALVES, D. K. Educação inclusiva: criatividade e ecoformação no entorno escolar. In: ZWIEREWCZ, M.; TORRE, S. De La. Uma escola para o Século XXI: Escolas criativas e resiliência na educação. Florianópolis: Insular, 2009.

REIMERS, F. M.; SCHLEIDER, A. A framework to guide na education response to the COVID-19 Pandemic of 2020. OECD, 2020. 
RIBEIRO O. C.; MORAES, M. C. Criatividade em uma perspectiva transdisciplinar: rompendo crenças, mitos e concepções. Brasília: Liber Livro, 2014.

SANTOS, A.C.S.; SANTOS, S. Hibridismo nas Práticas Inter/Transdiciplinares: reducionismo ou articulação. In: BEHRENS, M. A.; ENS, R. T. Complexidade e Transdisciplinaridade: novas perspectivas teóricas e práticas para a formação de professores. Curitiba: Appris, 2015.

SUANNO, M. V. R. Outra finalidade para a educação: emerge uma didática complexa e transdisciplinar. In: ZWIEREWICZ, M. Criatividade e Inovação no Ensino Superior: experiências latino-americanas e europeias em foco. Florianópolis: Nova Letra Editora, 2013.

SUANNO, J. H. Transdisciplinaridade, Criatividade e o Terceiro incluído na Formação de Professores. In: BEHRENS, M. A.; ENS, R. T. Complexidade e Transdisciplinaridade: novas perspectivas teóricas e práticas para a formação de professores. Curitiba: Appris, 2015.

TORRE, S. De La; ZWIEREWICZ, M. Projetos criativos ecoformadores. In: ZWIEREWCZ, M.; TORRE, S. De La. Uma escola para o Século XXI: Escolas criativas e resiliência na educação. Florianópolis: Insular, 2009.

TRIANDIS, H. C. Self-deception: An Introduction. Acta de Investigación Psicológica, v. 3, n. 2, p. 1069-1078, 2013.

UNESCO. Educação para os objetivos de desenvolvimento sustentável. Paris, 2017.

VASCONCELLOS, M. J. E. Pensamento Sistêmico: o novo paradigma da ciência. Campinas, SP. Papirus, 2002.

VESTENA, L. B.; VESTENA, C. L. B. A Espacialização da COVID-19 no Contexto dos Desastres 'Naturais': uma contribuição para educação. Revista Giramundo, Rio de Janeiro, v. 7, n. 13, 2020 (no prelo).

ZWIEREWICZ, M. Criatividade e Inovação no Ensino Superior: experiências latino-americanas e europeias em foco. Florianópolis: Nova Letra Editora, 2013.

ZWIEREWICZ, M.; SOUZA, J.; VEBER, S. C.; FERREIRA, H. M.; VESTENA, C. L. B.; BERG, J. Das abordagens do ensino do século $X X$ à educação complexa e aos projetos criativos ecoformadores. Revista Querubim, v. 15, p. 113-123, 2019. (Coletânea). 